\title{
The importance of meteorological scales to forecast air pollution scenarios on coastal complex terrain
}

\author{
J. L. Palau, G. Pérez-Landa, J. J. Diéguez, C. Monter, and M. M. Millán \\ Fundación Centro de Estudios Ambientales del Mediterráneo (CEAM), València, Spain
}

Received: 25 May 2005 - Published in Atmos. Chem. Phys. Discuss.: 12 July 2005

Revised: 29 September 2005 - Accepted: 29 September 2005 - Published: 21 October 2005

\begin{abstract}
Some of the meteorological approaches commonly considered in urban air pollution models do not take into account the importance of the smaller scales in the meteorology of complex-terrain coastal sites. The aim of this work is to estimate the impact of using the proper meteorological scales when simulating the behaviour of the pollutant concentrations emitted in the lower layers over coastal complex terrain areas. The availability of experimental measurements of a power plant plume near the Castellón conurbation (on the Spanish Mediterranean coast) has allowed us to use this plume as a tracer of opportunity of the lower atmosphere to check the results of a simulation exercise using the RAMS mesoscale model coupled to the HYPACT particle model. The results obtained show that in a complex-terrain coastal site, because of the strong effect of the meteorological interactions between the different scales on the integral advection and the turbulent dispersion of pollutants, using an inadequate scale to solve the meteorology can result in a very big gap in the simulation of lower-layer pollutant behaviour at urban scales.
\end{abstract}

\section{Introduction}

In recent years, different research projects around the world have evidenced that the formation and distribution of primary pollutants and photo-oxidants in urban plumes, at regional or continental scales, in the boundary layer and in the free troposphere, are all linked together (Millán et al., 1992; Fast et al., 1998; Menut et al., 1999, 2005; Dupont et al., 1999; Alonso et al., 2000; Fiore at al., 2002; Millán et al., 2002; Snyder, 2002; Gerbig et al., 2003; Rotach et al., 2004; Weigel et al., 2004; Weigel and Rotach, 2004; and e.g., webpages of the research projects ECLAP; MAP-Riviera; ES-

Correspondence to: J. L. Palau

(jlp@confluencia.biz)
COMPTE; VOTALP I and II; PACIFIC2001; AIR4EU; COBRA2000; COBRA-NA2003). Experimental data and complementary modelling results from different research projects have studied links between atmospheric circulations from local, through regional, to sub-continental scales, particularly in summer and in the Mediterranean basin (Millán et al., 1992, 2002).

The evidence collected to date from urban monitoring networks shows that photochemical air-quality problems in southern Europe, as in other mid-latitude regions throughout the world, are governed by meteorological processes with marked diurnal cycles and space scales of tens-to-hundreds of $\mathrm{km}$ which are not associated exclusively to classical seabreeze-type circulations (Lalas et al., 1983; Millán et al., 1984, 1987, 2000; Steyn, 1996; Fast and Zhong, 1998; Gangoiti et al., 2002; Menut et al., 2005).

Over complex terrain the properties of the lower troposphere strongly depend on the thermally induced local circulations that develop under clear sky conditions. Many studies have examined the daytime evolution of these processes. Whiteman (1982) observed the development of the boundary layer in mountain valleys, indicating that local subsidence influences convective boundary layer formation. Segal et al. (1988a) evaluated the impact of valley/ridge circulations on regional transport. In complex-terrain coastal areas the aforementioned "local circulations" couple with sea breezes to merge into a new and stronger thermal circulation.

The sea-breeze diurnal cycle associated with land-water temperature contrast, vertical structure, depth, return current, horizontal extent and life cycle has been observed in many coastal areas (Atkinson, 1981; Pielke, 1984). Likewise, the influence that increased stability due to subsidence offshore has on breeze development was documented by Mizzi and Pielke (1984). Other studies using numerical meteorological models (Mahrer and Pielke, 1977) have shown that the combination of sea breeze and mountain circulations induces more intense circulations than does each separately

(C) 2005 Author(s). This work is licensed under a Creative Commons License. 
(synergistic effect). In this sense, Kurita et al. (1985), Assai and Mitsumoto (1978) and Ookouchi et al. (1978) showed that mountains ranges contribute to intensify the sea breeze due to the thermal effect. Moreover, surface heat flux differences of $100 \mathrm{~W} / \mathrm{m}^{2}$ over several tens of kilometres due to physiographic differences on the surface can generate seabreeze-like circulations (Segal et al., 1988b).

In the case of Spain, experimental results up to 1987 showed that the observed sea breeze could be caused by a forcing mechanism which acts at larger scales than the purely local one and is associated with the formation of the Iberian Thermal Low (ITL) between late spring and the beginning of autumn (Millán et al., 1991, 1992). These meteorological interactions between different scales strongly affect the integral advection and the turbulent dispersion (Moran, 2000) of atmospheric pollutants at different times and distances between emission sources and impacts areas (Kallos et al., 1998; Millán et al., 1992, 1997, 2000; Gangoiti et al., 2001, 2002).

With respect to the representativeness of these kind of forcings (under summer anticyclonic conditions with low synoptic isobaric gradients), results from MECAPIP and RE$\mathrm{CAB}$ projects showed that the Thermal Low over the Iberian Peninsula acquires a quasi-permanent character in summer and constitutes the most frequent surface meteorological situation (Fig. 1, from the EC-funded RECAB project).

Because all these results show a mosaic of processes interacting at different scales synergistically, with a selforganization of the local flows at the regional level (Millán et al., 1997, 2002), it is necessary to consider the mesoscale circulations as a whole to be able to characterise the pollutant advection on mid-latitude complex terrain coastal areas (Kallos et al., 1998; Salvador et al., 1999; Gangoiti et al., 2001), (as is the case for the Spanish Mediterranean Coast). Thus, we took this approach into account to design both a modelling strategy to simulate pollutant transport and an Air Quality Forecasting System for photochemical air pollution scenarios on complex terrain (within the context of the ECfunded project FUMAPEX - "Integrated Systems for Forecasting Urban Meteorology, Air Pollution and Population Exposure").

The aim of the present work is thus to estimate the impact of applying incorrect meteorological scales when simulating the behaviour of pollutant concentrations emitted in the lower layers of coastal complex terrain areas. The experimental data for this study were obtained during the BEMA Step 1 campaign, which used an $\mathrm{SO}_{2}$ plume emitted from a power plant near the Castellón conurbation (Fig. 2a) as a tracer of opportunity of the lower atmosphere. With these data we check the results of a simulation exercise using the RAMS mesoscale model coupled to the HYPACT particle model. Our results point out the dependence between the simulation of lower-layer pollutant behaviour and the ability of operational meteorological models to correctly reproduce the daily cycle of the lower atmosphere.

\section{Study area}

The Castellón area (North of Valencia) is located on the east coast of the Iberian Peninsula in the Western Mediterranean Basin (Fig. 2a). The Castellón coastal plain (characterised by irrigated-crops vegetation) is delimited on the North, at $7 \mathrm{~km}$ from the coast, by a mountain range averaging $780 \mathrm{~m}$ above sea level, m.a.s.l. (with a very steep slope towards the coastal side), and on the west, at 20 -to- $30 \mathrm{~km}$ from the coast, by the Iberian mountain range (with Mediterranean forest and a mean altitude of 1000 to $1300 \mathrm{~m}$ a.s.l.), which runs parallel to the coast.

Under typical summer conditions the surrounding mountains are strongly heated during the day favouring the development of upslope winds, which combine with the sea breezes and the compensatory flows over the coast. During the night these processes relax and drainage flows are dominant over the surface. This typical daily cycle can be explained as a combination of local and regional forcing (Millán et al., 2000).

Studies on the historical meteorological data (Bolle, 2003; Palau, 2003; Millán et al., 2004) show that the sea-breeze cycle developes all year long under anticyclonic conditions (associated with a low synoptic isobaric gradient). Under this meteorological scenario, two predominant wind-field directions occur on this site. One corresponds to the daytime sealand breeze with an east to south-southeast direction, and the second corresponds to the night-time land-sea breeze with a west to northwest direction .

\section{Methodology}

\subsection{Experimental setup}

Within the context of the EC-funded project BEMA Step 1 (Biogenic Emissions in the Mediterranean Area), experimental measurements were taken using two vehicles (mobile units), both instrumented with a COrrelation SPECtrometer (COSPEC) for recording the distribution of pollutants aloft (Millán et al., 1976). The COSPEC is a passive remote sensor that uses the sunlight dispersed in the atmosphere as its radiation source. Its response is proportional to the vertically - integrated $\mathrm{SO}_{2}$ concentration (throughout the optic path between the infinitum and the instrument telescope, Millán et al., 1977).

Measurements were taken around a power plant located near the Castellón conurbation, 2-to-3 km from the seashore. This power plant has two $540 \mathrm{MW}$ units, each with a 150 meter-tall stack. In the plume-measurement strategy, both mobile unites (vehicles) made simultaneous transects around the Castellón conurbation at different distances from the stack (Fig. 2a). Measurements were taken throughout the day to record any changes that might occur in the plume transport direction or in the dispersive conditions. Thus, using this 


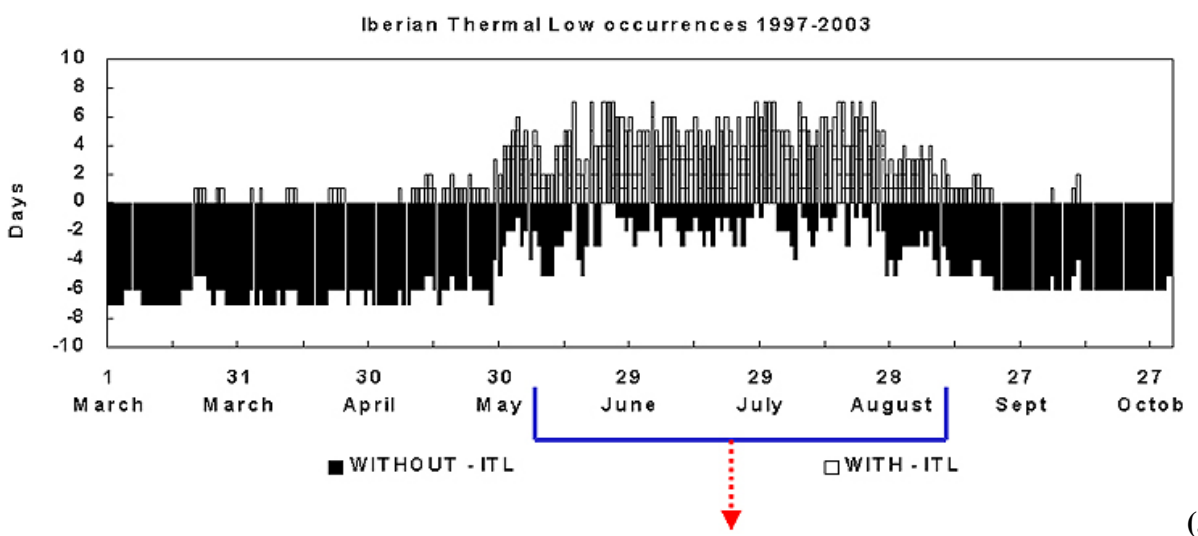

(a)

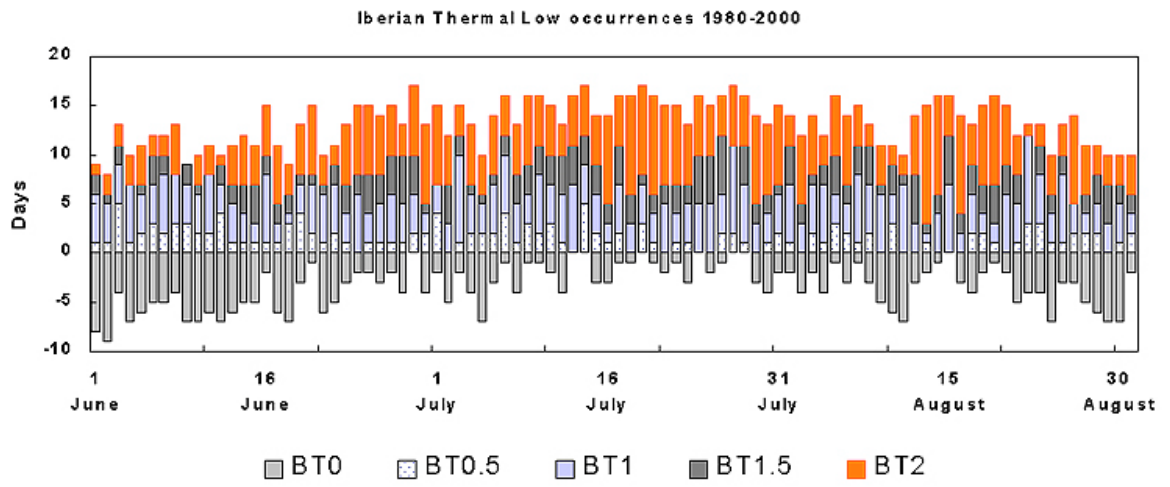

(b)

Fig. 1. (a) Iberian Thermal Low (ITL) occurrences between 1997 and 2003; negative values indicate that no ITL was recorded on the Iberian Peninsula, and positive values indicate the number of ITL occurrences on each day of the month during this seven-year period. (b) Number of ITL formations in summer during a twenty-year period (1980-2000); disaggregation of ITL types was performed on the basis of the intensity (isobaric gradient in the synoptic analysis charts) of the ITL formed each day. BT2 indicates the ITL highest strength (number of days when the ITL was shown as a closed loop of low pressure at both 12:00 UTC and 18:00 UTC on the Iberian Peninsula) and BT0.5 indicates the number of days the thermal low appeared just as an open loop of low pressure over the Iberian Peninsula at 12:00 UTC. BT0 indicates the number of days with no ITL formation (negative numbers in the graph). Data was obtained from the EC-funded project RECAB (2000-2003); more info is available in the final report of that project.

plume as a tracer of opportunity of the lower atmosphere, it was possible to track the daily evolution of the wind field and the dispersive conditions (as previously performed in other experiments in different regions, Millán et al., 1979; Guillot et al, 1979; Chung et al., 1981; Hoff et al., 1982; Portelli, 1982; Millán et al., 1987; Eastman et al., 1995; Palau, 2003).

Moreover, there are eleven sets of measurements obtained from the Regional Air Quality Network (measuring continuously air pollutants and meteorological parameters), and from meteorological towers installed during the BEMA campaign. The available meteorological data were recorded electronically every $15 \mathrm{~min}$ (wind direction and wind speed, at $10 \mathrm{~m}$ above the ground, and temperature at $2 \mathrm{~m}$ above the ground). Sensors are located on different sites in the study area (Fig. 2).

\subsection{Model configuration}

In this study we used the mesoscale meteorological model, Regional Atmospheric Modeling System (RAMS version 4.3.0 - Pielke et al., 1992) coupled to the RAMS HYbrid Particle And Concentration Transport model (HYPACT version 1.2.0 - Tremback et al., 1993). The RAMS model is quite flexible and includes different options for parameterising physical processes. In this study the turbulence parameterisation used was a TKE level 2.5 scheme (Mellor and Yamada, 1982). Surface layer fluxes were obtained with the Louis (1979) scheme. The shortwave and longwave radiation parameterisation applied was a full-column two-stream single-band radiation scheme (Chen and Cotton, 1983). The LEAF-2 soil-vegetation model calculates the sensible, latent and soil heat fluxes exchanged with the atmosphere, using prognostic equations for soil moisture and temperature (Walko et al., 2000). 

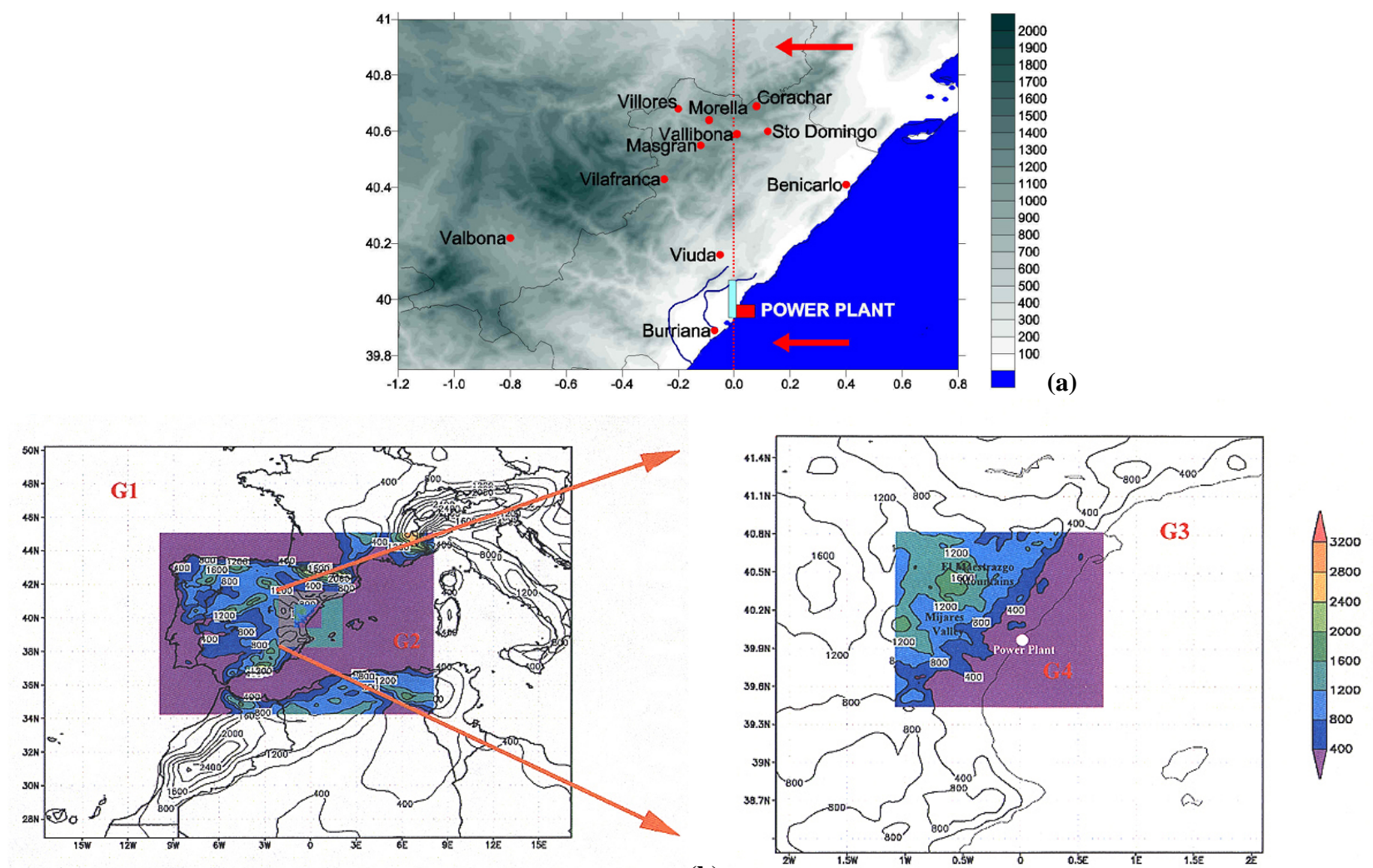

(b)

Fig. 2. (a) Study area in eastern Spain; the eleven meteorological towers providing experimental measurements are marked with red points. Vertical (longitudinal) red line indicates the transversal section used for generating Figs. 8 to 11 . Road network used by the two mobile units (instrumented with a COSPEC) to take measurements around the power plant is also indicated. (b) and (c): modelling configuration with the four grids of different resolution employed in the simulations centred over the Castellón power plant $\left(\mathrm{G}_{1} 40.5 \mathrm{~km}, \mathrm{G}_{2} 13.5 \mathrm{~km}, \mathrm{G}_{3} 4.5 \mathrm{~km}\right.$, $\left.\mathrm{G}_{4} 1.5 \mathrm{~km}\right)$.

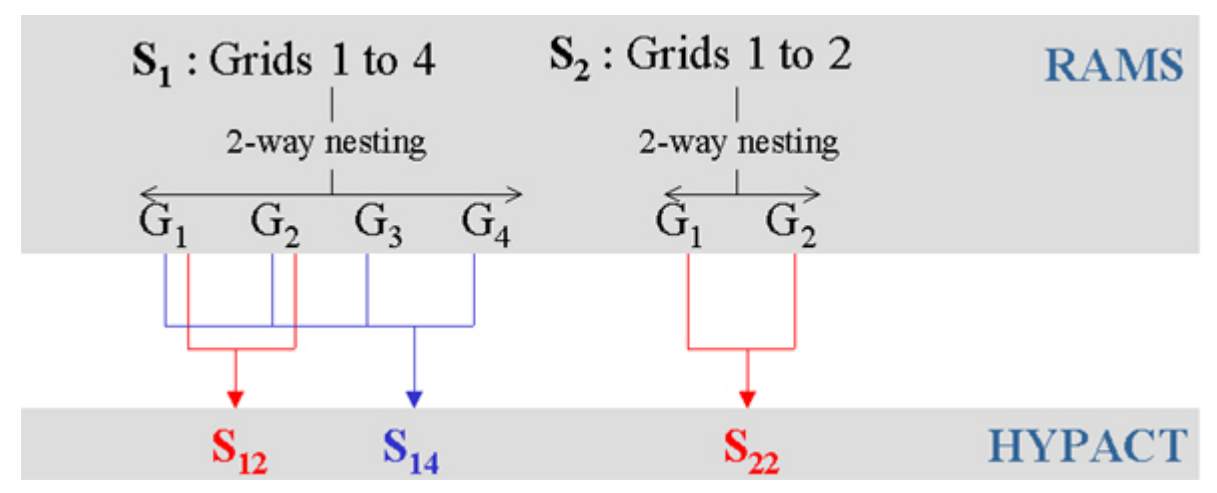

Fig. 3. Modelling scheme followed during the simulation exercise. For the first meteorological simulation $\left(\mathrm{S}_{1}\right)$ four domains were employed in the meteorological model (RAMS) with two-way nesting domains. Results were obtained for grids $\mathrm{G}_{1}$ to $\mathrm{G}_{4}$. To perform the HYPACT simulations $\left(S_{12}\right.$ and $S_{14}$ ), two different configurations were employed: using only the $G_{1}$ and $G_{2}$ grids from RAMS (simulation $S_{12}$ ), and using the four domains from RAMS $\left(S_{14}\right)$. The second meteorological simulation $\left(S_{2}\right)$ was configured with the $G_{1}$ and $G_{2}$ domains only (two-way nested). Its solution was fed into the HYPACT particle model, generating a new solution ( $\mathrm{S}_{22}$ ). All results are compared and discussed in the present paper. Meteorological fields within $\mathrm{G}_{4}$ and HYPACT results within $\mathrm{S}_{14}$ are used for validating purposes; meteorological fields in $\mathrm{G}_{2}$ (for both meteorological simulations) and HYPACT results within $S_{12}$ and $S_{22}$ are used to evaluate the importance of meteorological scales to forecast air pollution scenarios. 
Table 1. Configuration of the Mesometeorological Model - RAMS, and the Lagrangian Particle Dispersion Model - HYPACT.

\begin{tabular}{ll}
\hline Meteorological Model & RAMS v. 4.3 .0 \\
\hline Domain & 4 nested domains. Grids: $89 \times 73,125 \times 95,83 \times 83,104 \times 104$ \\
Horizontal grid size & Inner domain: $1.5 \mathrm{~km}$ (stretching ratio:3) \\
Vertical resolution & 45 sigma levels with geometric stretching $(16$ levels in the first $1000 \mathrm{~m})$ \\
Boundary \& Initial Conditions & NCEP Reanalysis data \\
\hline LPD Model & HYPACT v.1.2.0 \\
\hline Domain & RAMS domains \\
Resolution & RAMS resolution \\
Source & 400000 particles in $54 \mathrm{~h} ; 175 \mathrm{~m}$ a.g.l \\
Input analysis variables & 10 min \\
\hline
\end{tabular}

We performed simulations of the RAMS coupled to HYPACT model (Tables 1 and 2) for 17, 18 and 19 July 1995, to check the effect of different meteorological approaches on the simulation of pollutant behaviour in a complex terrain coastal area. For this, two different meteorological configurations of the RAMS model were employed, but, in both cases, the same initial and boundary conditions were used: a) Simulation $1\left(S_{1}\right)$, using four nested domains centred over the Castellón power plant (with grid size of: $G_{1}$ (grid one) $40.5 \mathrm{~km}, \mathrm{G}_{2} 13.5 \mathrm{~km}, \mathrm{G}_{3} 4.5 \mathrm{~km}, \mathrm{G}_{4} 1.5 \mathrm{~km}$ ), and b) Simulation $2\left(\mathrm{~S}_{2}\right)$, using only the outer two nested domains (with the same resolutions and boundaries as the aforementioned $\mathrm{G}_{1}$ and $\mathrm{G}_{2}$ ).

It is important to note that both configurations permit twoway nesting between grids (Table 2 and Fig. 3 ) with the only difference between them being that simulation $S_{1}$ resolves the meteorology by considering $1.5 \mathrm{~km}$ as the smallest grid size while simulation $S_{2}$ resolves the meteorology without feedback from the two inner domains; i.e., by considering $13.5 \mathrm{~km}$ as the lowest grid size (Fig. $2 \mathrm{~b}$ and c). Thus, the meteorology resolved within the second grid $\left(\mathrm{G}_{2}\right)$ for both simulations differs strictly in the fact that in the first case $\left(\mathrm{S}_{12}\right)$, the results are consistent with inner domains feedback (i.e., the model resolves the inner domain meteorology) while in the second simulation $\left(S_{22}\right)$, there is no inner domains feedback because $\mathrm{G}_{2}$ is the highest resolution domain.

RAMS output fields were obtained every $10 \mathrm{~min}$ to avoid time steps too big for dispersive simulations under seabreeze-type circulations. The HYPACT model was run using the Lagrangian dispersion scheme with 3-D wind and turbulence fields provided by the three RAMS outputs $\left(\mathrm{S}_{14}\right.$, $\mathrm{S}_{12}$, and $\mathrm{S}_{22}$ ) (Table 2 and Fig. 3). This model was employed to both simulate the $\mathrm{SO}_{2}$ emissions from the power plant and analyse the effect that the different meteorological fields obtained within the second domain (simulations $\mathrm{S}_{1}$ and $\mathrm{S}_{2}$ ) have on the dispersive pattern of the $\mathrm{SO}_{2}$ plume. The atmospheric dispersion was simulated as emitting, at $175 \mathrm{~m}$ a.g.l., 400000 particles at a constant rate for $54 \mathrm{~h}$. The
Table 2. Modelling Strategy. Simulation $\mathrm{S}_{14}$ was performed with four nested domains and a $1.5 \mathrm{~km}$ horizontal grid size in the inner domain. Simulation $\mathrm{S}_{12}$ corresponds to the simulation within the second domain (13.5 km horizontal grid size), but considering feedbacks from the four nested domains. Simulation $\mathrm{S}_{22}$ was performed with only two nested domains and a $13.5 \mathrm{~km}$ horizontal grid size in the inner domain.

\begin{tabular}{ccc}
\hline Simulation & Grid size (grid number) & Nesting and grids considered \\
\hline $\mathrm{S}_{14}$ & $1.5 \mathrm{~km}\left(\mathrm{G}_{4}\right)$ & 2-way; grids 1 to 4 \\
$\mathrm{~S}_{12}$ & $13.5 \mathrm{~km}\left(\mathrm{G}_{2}\right)$ & 2-way; grids 1 to 4 \\
$\mathrm{~S}_{22}$ & $13.5 \mathrm{~km}\left(\mathrm{G}_{2}\right)$ & 2-way; grids 1 to 2 \\
\hline
\end{tabular}

trajectories were calculated by making use of the average wind fields, and the turbulence velocities by resolving the Langevin equation with a Markov process (Legg and Raupach, 1982). Uliasz (1994) provides information about the physical parameterisations developed for the HYPACT. Input analysis variables from the RAMS simulations were $10 \mathrm{~min}$ each. To simulate the dispersion of pollutants under different meteorological approaches, the HYPACT (Lagrangian) output for the first RAMS simulation $\left(S_{1}\right)$, the $1.5 \mathrm{~km}$ grid size domain is denoted as $\mathrm{S}_{14}$; the Lagrangian output for the very same simulation but considering only the wind fields in the first two grids, i.e. reaching the $13.5 \mathrm{~km}$ grid size domain, is denoted as $S_{12}$. The output for the second RAMS simulation $\left(S_{2}\right.$; for the $13.5 \mathrm{~km}$ grid size domain) is denoted as $S_{22}$ (Fig. 3).

\subsection{Model validation}

To validate these simulations, within the higher resolution domain, we followed two different and independent procedures, as suggested in various papers dealing with meteorological and air quality model validations (Willmott, 1981; Pielke, 1984; Uliasz, 1994; Stauffer and Seaman, 1990; Fast, 1995; Uliasz et al., 1996; Pielke and Uliasz, 1997; Seaman, 
Table 3. Average observational and modelled values (AvObs and AvMdl), Bias, Root Mean Square Error (RMSE) of temperature (at $2 \mathrm{~m}$ a.g.1.) and wind speed (at $10 \mathrm{~m}$ a.g.1.), RMSE-vwd (RMSE of the horizontal vector-wind-difference), at eleven different sites (see geographical locations in Fig. 2) for the three days simulated. Value on all stations during the three simulated days has been calculated on a total of 729 values for $1 \mathrm{~h}$-averaged temperature and 727 values for $1 \mathrm{~h}$-averaged wind speed (Nobs). In addition, the I.A. (Index of Agreement) value is calculated as the average of the eleven different sites (index of agreement of 729 pairs of values for temperature and 727 pairs of values for wind speed).

\begin{tabular}{|c|c|c|c|c|c|c|c|}
\hline Station & NObs & AvObs & AvMdl & Bias & RMSE & RMSE-vwd & I. A. \\
\hline \multicolumn{8}{|c|}{ Wind speed at $10 \mathrm{~m}$ a.g.l. } \\
\hline BENICARLO & 67 & 2.5 & 2.3 & -0.2 & 0.9 & 1.7 & $* * *$ \\
\hline BURRIANA & 67 & 1.9 & 2.0 & 0.1 & 1.0 & 1.5 & $* * *$ \\
\hline VIUDA & 67 & 1.8 & 2.4 & 0.7 & 1.2 & 2.3 & $* * *$ \\
\hline STO DOMINGO & 67 & 3.3 & 2.4 & -0.8 & 1.2 & 2.1 & $* * *$ \\
\hline VALBONA & 67 & 2.2 & 2.6 & 0.4 & 1.0 & 1.1 & $* * *$ \\
\hline VILAFRANCA & 59 & 2.8 & 3.0 & 0.3 & 1.2 & 2.5 & $* * *$ \\
\hline MAS GRAN & 67 & 3.7 & 2.8 & -0.9 & 1.7 & 2.1 & $* * *$ \\
\hline VALLIBONA & 67 & 3.5 & 2.4 & -1.1 & 1.9 & 2.2 & $* * *$ \\
\hline MORELLA & 65 & 4.2 & 2.9 & -1.3 & 1.6 & 2.1 & $* * *$ \\
\hline CORACHAR & 67 & 2.4 & 2.6 & 0.2 & 1.2 & 1.5 & $* * *$ \\
\hline VILLORES & 67 & 3.3 & 2.1 & -1.1 & 1.8 & 2.4 & $* * *$ \\
\hline Value on all stations & 727 & 2.9 & 2.5 & -0.3 & 1.4 & 1.9 & 0.82 \\
\hline \multicolumn{8}{|c|}{ Temperature at $2 \mathrm{~m}$ a.g.l. } \\
\hline BENICARLO & 67 & 26.6 & 28.3 & 1.7 & 2.1 & $* * *$ & $* * *$ \\
\hline BURRIANA & 67 & 27.1 & 28.0 & 0.8 & 1.6 & $* * *$ & $* * *$ \\
\hline VIUDA & 67 & 25.2 & 29.7 & 4.5 & 5.0 & $* * *$ & $* * *$ \\
\hline STO DOMINGO & 67 & 24.0 & 26.6 & 2.6 & 3.1 & $* * *$ & $* * *$ \\
\hline VALBONA & 67 & 24.5 & 27.0 & 2.5 & 3.3 & $* * *$ & $* * *$ \\
\hline VILAFRANCA & 59 & 21.7 & 25.0 & 3.3 & 3.7 & $* * *$ & $* * *$ \\
\hline MAS GRAN & 67 & 25.0 & 26.3 & 1.3 & 2.4 & $* * *$ & $* * *$ \\
\hline VALLIBONA & 67 & 21.7 & 25.5 & 3.8 & 4.2 & $* * *$ & $* * *$ \\
\hline MORELLA & 67 & 24.2 & 26.4 & 2.2 & 2.8 & $* * *$ & $* * *$ \\
\hline CORACHAR & 67 & 22.7 & 25.7 & 3.0 & 3.5 & $* * *$ & $* * *$ \\
\hline VILLORES & 67 & 26.7 & 29.5 & 2.8 & 3.7 & $* * *$ & $* * *$ \\
\hline Value on all stations & 729 & 24.5 & 27.1 & 2.6 & 3.5 & $* * *$ & 0.77 \\
\hline
\end{tabular}

2000; Hanna and Yang; 2001). Both validation procedures utilised the simulated results obtained with the highest resolution domain (simulation $S_{1}$, reaching grid 4) to account for terrain influence on the atmospheric flows (Salvador et al., 1999).

The first validation exercise checked the RAMS results against the available experimental measurements of meteorological parameters (temperature, wind speed and wind direction) from eleven meteorological towers located within the inner domain $\left(\mathrm{G}_{4}\right)$, Fig. 2a. During this first meteorologicalfield validation process, the temporal series of measurements and the corresponding modelled magnitudes were plotted for visual intercomparison. Besides comparing the temporal series, we also made statistical calculations (on Bias, Root Mean Square Error (RMSE), Root-Mean-Square vectorwind-difference Error (RMSE-vwd), Index of Agreement (I.A.), observed averaged (AvObvs) value and modelled averaged (AvMdl) value) for the temperature at $2 \mathrm{~m}$ above ground level (m a.g.l.) and the wind speed at $10 \mathrm{~m}$ a.g.l.; Ta- ble 3). Bias (or mean bias, Pielke, 1984) is defined as the average of the simulated value minus the observed value; it quantifies the systematic error of the model. RMSE (Pielke, 1984 ) is the square root of the individual differences between simulated and observed values; it quantifies the accuracy of the model. RMSE-vwd (Pielke, 1984; Fast, 1995) is the RMSE of the horizontal vector-wind-difference. I.A. (Willmott, 1981) is the ratio between the Mean Square Error and the "Potential Error" (where "Potential Error" specifies the degree to which the observed deviations in the mean observation correspond, both in magnitude and sign, to the predicted deviations in the mean observation). This dimensionless statistic reflects the degree to which the observed variate is accurately estimated by the simulated variate. It varies from 0.00 and 1.00 .

The second validation exercise consisted of using the dispersion measurements of the plume aloft to validate the results obtained from the $\mathrm{S}_{14}$ dispersive simulations, Table 2, (performed with the HYPACT model using the 
meteorological fields produced by RAMS and previously validated). Using the plume measurements aloft as a tracer of opportunity of the wind field at the plume transport height, the simulated dispersion results were compared with the experimental measurements (taken, as described before, with two mobile units driving around the power plant at different times of the day). During this second validating process, we checked the daily evolution in the experimental and simulated integral advections of the plume aloft and evaluated the ability of the model to reproduce the daily cycle of the wind field (associated, as aforementioned, with the development of thermal mesoscale circulations).

\section{Experimental campaign}

During the campaign analysed (on 17, 18 and 19 July 1995), typical summer conditions prevailed over the Iberian Peninsula, dominated by the influence of the Atlantic Anticyclone, which extended towards Central-Europe and the Western Mediterranean Basin. Under such conditions, a zone of thermal low pressure associated with the semipermanent Sahara Low formed over the Iberian Peninsula.

On 17 July 1995, a complete daily cycle of the sea breeze was tracked using the $\mathrm{SO}_{2}$ emissions from the Castellón coastal power plant. In the present paper we discuss three situations that develop during this time period, corresponding to three different stages in the sea breeze development. The first, at 07:00 UTC, corresponds to the nocturnal drainage flow (Fig. 5); the second (not shown), at 12:00 UTC, corresponds to a developed sea breeze with intense convective activity (along the Mijares valley, West of the Castellón Power Plant); the third, at 17:00 UTC, corresponds to the last experimental measurements available and shows a sea breeze driven by mesoscale features (along the Rambla de la Viuda towards the El Maestrazgo Mountains, NW of the Castellón Power Plant; Fig. 6).

The Mobile Unit (M.U.) records until 09:00 UTC locate the power plant plume South-East of the emission point, running parallel to the coastline within a stable stratum of the nocturnal drainage flow (Fig. 5b).

The sea breeze develops clearly from 08:00-09:00 UTC at the site located close to the power plant. From the M.U. records at 12:00 UTC, the plume is seen to be advected inland (flow from the East) while strong convective activity soon "disorganizes" the plume, spreading it over a wide area (not shown). The surface measurements continue to show winds from the Southeast. This is a sign of the complex vertical structure of the wind field, typical of Western Mediterranean coastal sites (as documented previously during the MECAPIP campaign; Millán et al., 1992).

The last M.U. record at 17:00 UTC evidences how the plume is being transported within a SE flow along the Rambla de la Viuda (Fig. 6b), while surface measurements at the coastal sites record ESE winds.

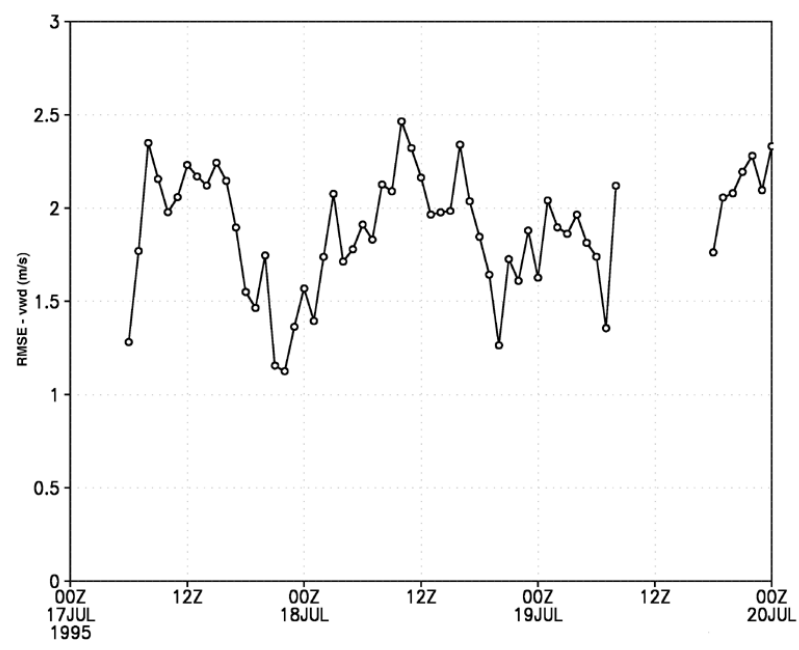

Fig. 4. Time series of the root-mean-square wind-vector-difference error (RMSE-vwd) for the near-surface wind field ( $10 \mathrm{~m}$ a.g.l.) as spatial average on all stations for simulation $S_{1}$ in grid $G_{4}$. The corresponding temporal average value over the three-day period is $1.9 \mathrm{~m} / \mathrm{s}$.

\section{Results and discussion}

\subsection{Results of the validation}

To validate the model skills, the simulated meteorological data on temperature, wind speed and wind direction were compared with the experimental measurements at eleven different meteorological sites located within the inner domain, $\mathrm{G}_{4}$, (Fig. 2). In this paper, we include as representative of the model skills within the whole inner domain, the statistics obtained for temperature and wind for the eleven meteorological stations available (Table 3 and Fig. 4).

Logarithmic vertical interpolation between the lowest model layer $(14 \mathrm{~m})$ and the canopy temperature at the roughness height was performed to estimate simulated temperature at the measurements height $(2 \mathrm{~m})$. Although some significant differences in the model's skills were observed at the different stations due to terrain complexity, on average, for the temperature at $2 \mathrm{~m}$ a.g.l. a significant and systematic error of the model was detected (RMSE value of $3.5^{\circ} \mathrm{C}$ as temporal and spatial average on all stations). Therefore, bias and average values of the eleven stations show a clear overestimation of about $2.6^{\circ} \mathrm{C}$ probably due to topography complexity and to deficiencies in the initialisation of the thermodynamic properties of the soil which play a role in the simulated local energy budget. Moreover, it is important to note that the worst-simulated temperatures were found during the nocturnal hours, probably due to limitations of the RAMS primary boundary layer (PBL) parameterisation under stable conditions. Nocturnal cooling of the lower layers of the troposphere has not been well reproduced by the model in most of the sites within the inner domain. Nevertheless, 


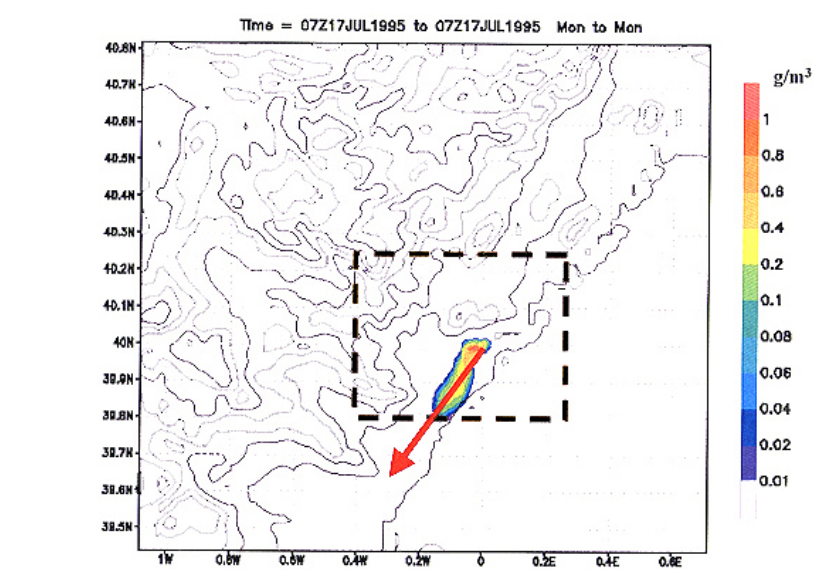

(a)

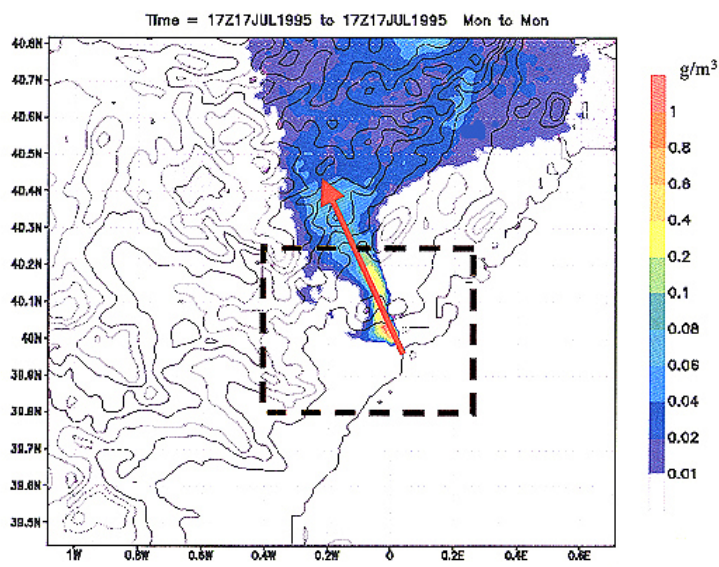

aros: couros

${ }^{2004-09-22-10225}$ (a)
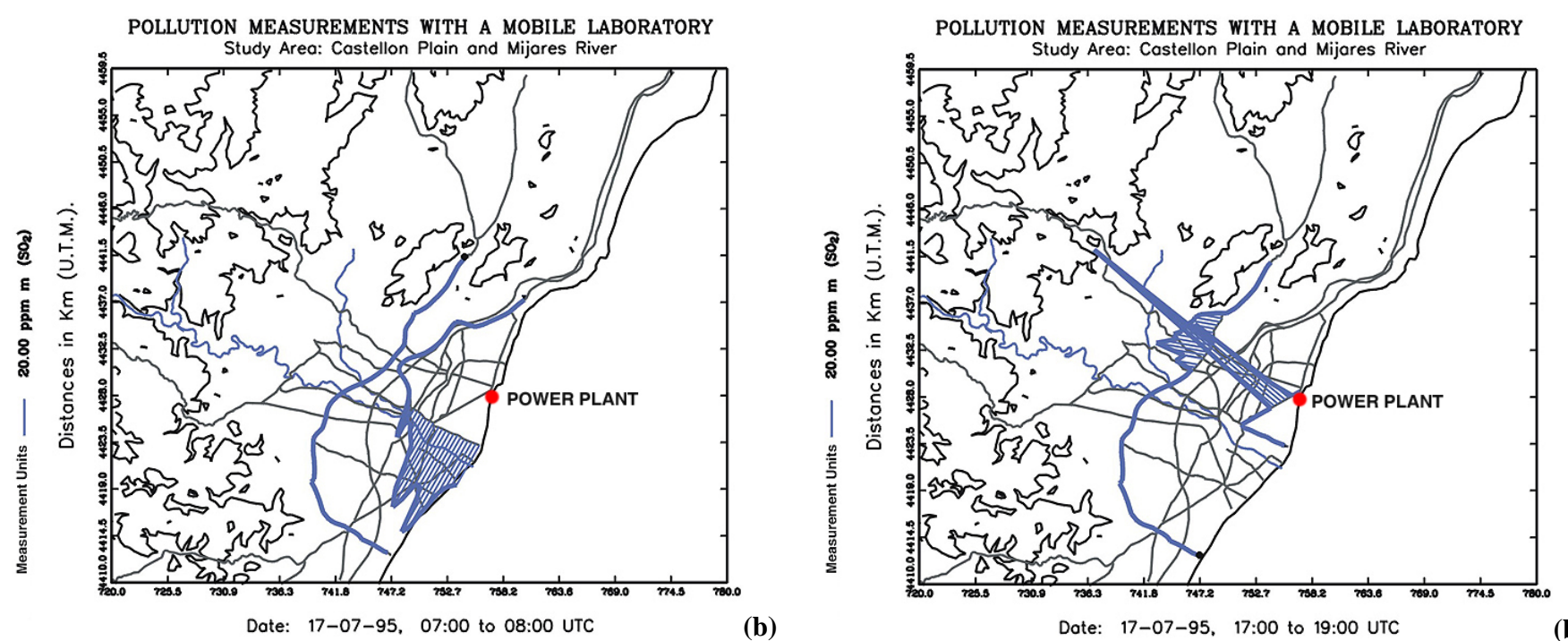

Fig. 5. Simulation $S_{14}$ with an inner domain of $1.5 \mathrm{~km}$, for 07:00 UTC on 17 July 1995: (a) modelling simulation results and (b) experimental measurements . During the early morning the plume is advected southward parallel to the coast within a stable stratum (nocturnal drainage winds). Black square in figure (a) indicates the experimental area plotted in (b). Red arrow indicates the mean plume transport direction.

index of agreement is 0.77 , i.e. daily and day-to-day evolution of temperature, is quite well reproduced by the model.

The meteorological observations of wind speed and direction were made at a height of $10 \mathrm{~m}$ a.g.l.; Louis similarity theory (1979) was used to adjust simulated wind speed at the height of the lowest model layer $(14 \mathrm{~m})$ to the measurements height $(10 \mathrm{~m})$. Under this summer three-days period (with clear skies and low surface wind speeds), the day-to-day results are fairly consistent and good results for the root-mean-square error (RMSE) of the wind speed at $10 \mathrm{~m}$ a.g.l. $(1.4 \mathrm{~m} / \mathrm{s})$ and of the vector-wind-difference at the same height $(1.9 \mathrm{~m} / \mathrm{s})$ were obtained (Table 3 and Fig. 4 ).

No systematic bias was observed in the model, and the mean bias value obtained $(-0.3 \mathrm{~m} / \mathrm{s})$ is the result of a sharp and non-skewed distribution around zero. Coherently, the index of agreement obtained for the whole measurements for the eleven stations ( 727 hourly values) was 0.82 (Table 3 ).

It is important to note that for light wind speeds (lower than $0.5 \mathrm{~m} / \mathrm{s}$ ), wind directions measured at the stations are known to be variable and unreliable. This feature makes it difficult to validate the simulated drainage winds on the basis of the wind direction. Nevertheless, by using air pollutants as tracers of opportunity during consecutive daytime periods (2-to-4 days or more), it is possible to infer the nocturnal 
dynamic of the winds, as well as directly validate the diurnal sea breezes (with wind speeds much higher than the nocturnal ones).

As a first result from the validation, it is important to note that, as the index of agreement for both magnitudes (temperature and wind speed) is the result of a spatial and temporal average over the whole $\mathrm{G}_{4}$ domain, the degree to which the observed variate is accurately estimated by the simulate variate is of $77 \%$ for temperature and of $82 \%$ for wind speed within the higher resolution domain.

Besides, before evaluating the impact of using different meteorological scales on the simulated wind fields, one further validating procedure was performed using the COSPEC $\mathrm{SO}_{2}$ measurements aloft during the three-days period.

To validate the wind fields aloft and to corroborate that the high horizontal resolution used (grid size of $1.5 \mathrm{~km}$ ) had correctly simulated the dynamic of the winds (sea breeze development and drainage winds) allowing us to reproduce the daily cycle of a point source plume on a coastal area with complex terrain, we compared the dispersive results obtained from the simulation $\mathrm{S}_{14}$ (Table 2) with the experimental measurements of the $\mathrm{SO}_{2}$ plume aloft.

The simulations of the power plant dispersion on 17 July are able to reproduce the complete daily cycle of the sea breeze when high resolution is employed. During the early morning hours, the simulated plume is advected within a stable stratum of the nocturnal drainage flowing parallel to the coast, as the experimental results show (Figs. 5a and b). At 12:00 UTC, the simulation shows how the sea breeze transports the plume inland, perpendicular to the coastline, and this is also seen in the measurements (not shown). Five hours later, in the afternoon, both the simulation and the measurements show that the plume turns N-NW with respect to the emission point (Figs. 6a and b).

Thus, as a second validation result, a horizontal resolution that enabled us to simulate the dynamic of the winds (sea breeze development and drainage winds), allowed us to reproduce the daily cycle of a point source plume in a coastal area with complex terrain.

\subsection{Effects of feedback from small scales}

To check the effect that the different resolved meteorological scales have on the simulation of pollutant behaviour in a complex-terrain coastal area, we compared two meteorological configurations of the RAMS model. As described before (within the "model configuration"), in both cases we have used the very same initial and boundary conditions; the only difference is that in simulation $S_{12}$ (Table 2) the grid-2 wind fields are coherent with the grid- 4 wind fields (because of the two-way nested configuration of the four domains); i.e., the meteorological solution in $\mathrm{S}_{12}$ has resolved the finer-scale meteorology. Moreover, simulation $\mathrm{S}_{22}$ has no finer-scale meteorological information because of the two-way nested configurations of just two domains (Table 2).

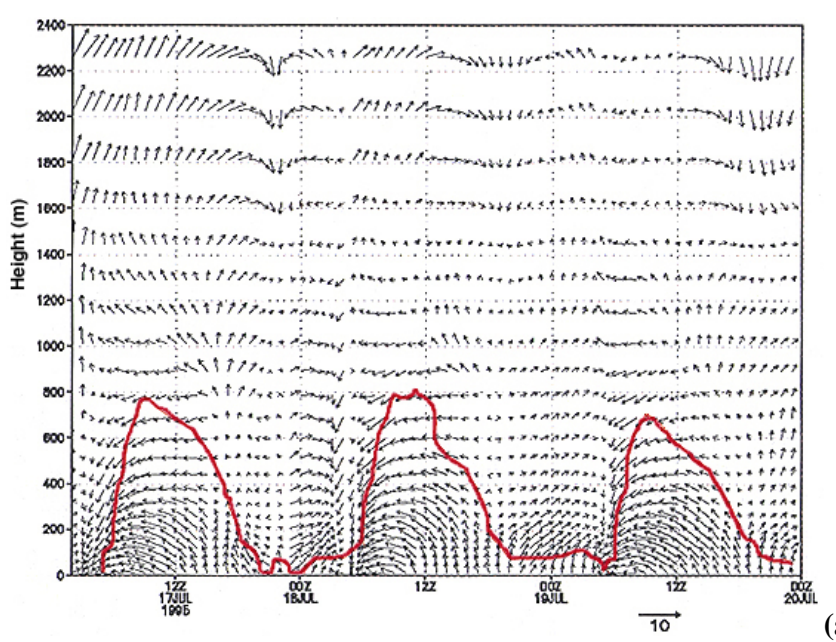

(a)

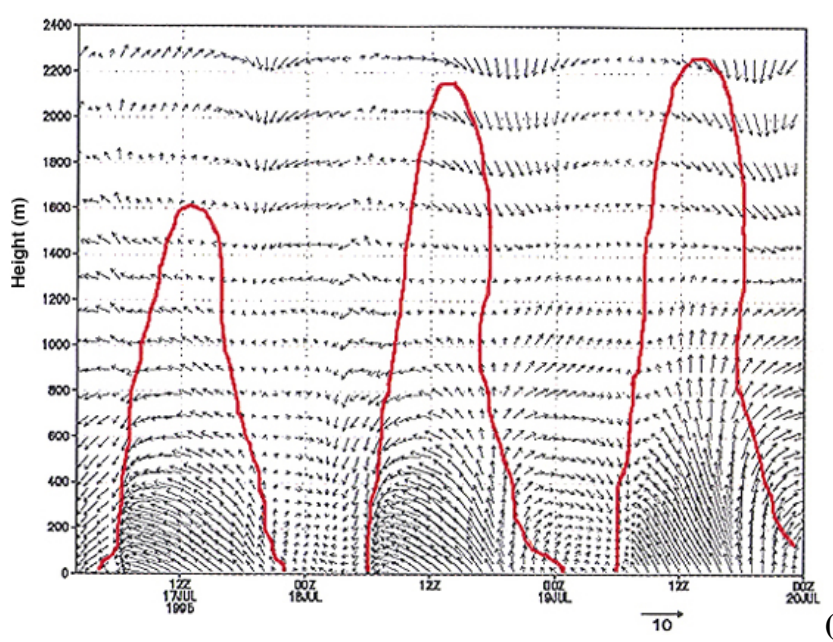

(b)

Fig. 7. Comparison between (a) meteorological simulation within $\mathrm{G}_{2}$ for simulation $\mathrm{S}_{1}$, i.e., with inner domain feedbacks and (b) meteorological simulation within the same grid $\mathrm{G}_{2}$ but for simulation $\mathrm{S}_{2}$, i.e., without inner domain feedbacks. In each simulation the PBL parameterisation behaviour is different. With feedback from the two higher resolution domains, a PBL height of $800 \mathrm{~m}$ a.g.l. is simulated. Without any feedback from higher resolution domains, a PBL height of $2100 \mathrm{~m}$ a.g.l. is obtained. It is also important to note the different wind-field structure due to feedback from inner domains (mainly during the nocturnal hours). These time series were obtained on the vertical of the power plant.

The $S_{12}$ wind-field simulation shows the daily cycle of the typical coastal flows with land-driven thermal circulations that die down during the night. In spite of the $13.5 \mathrm{~km}$ grid size, the early morning drainage winds to 07:00 UTC are captured by the $\mathrm{S}_{12}$ simulation, because of the model's ability to work with the information resolved within the inner domains (4.5 and $1.5 \mathrm{~km}$ ). With the $S_{22}$ simulation configuration (without inner domains), the wind field behaviour in the lower levels is essentially different from the previous case. It is of interest to note that the drainage wind is not reproduced during the night-time in the latter case (Fig. 7b). Another 

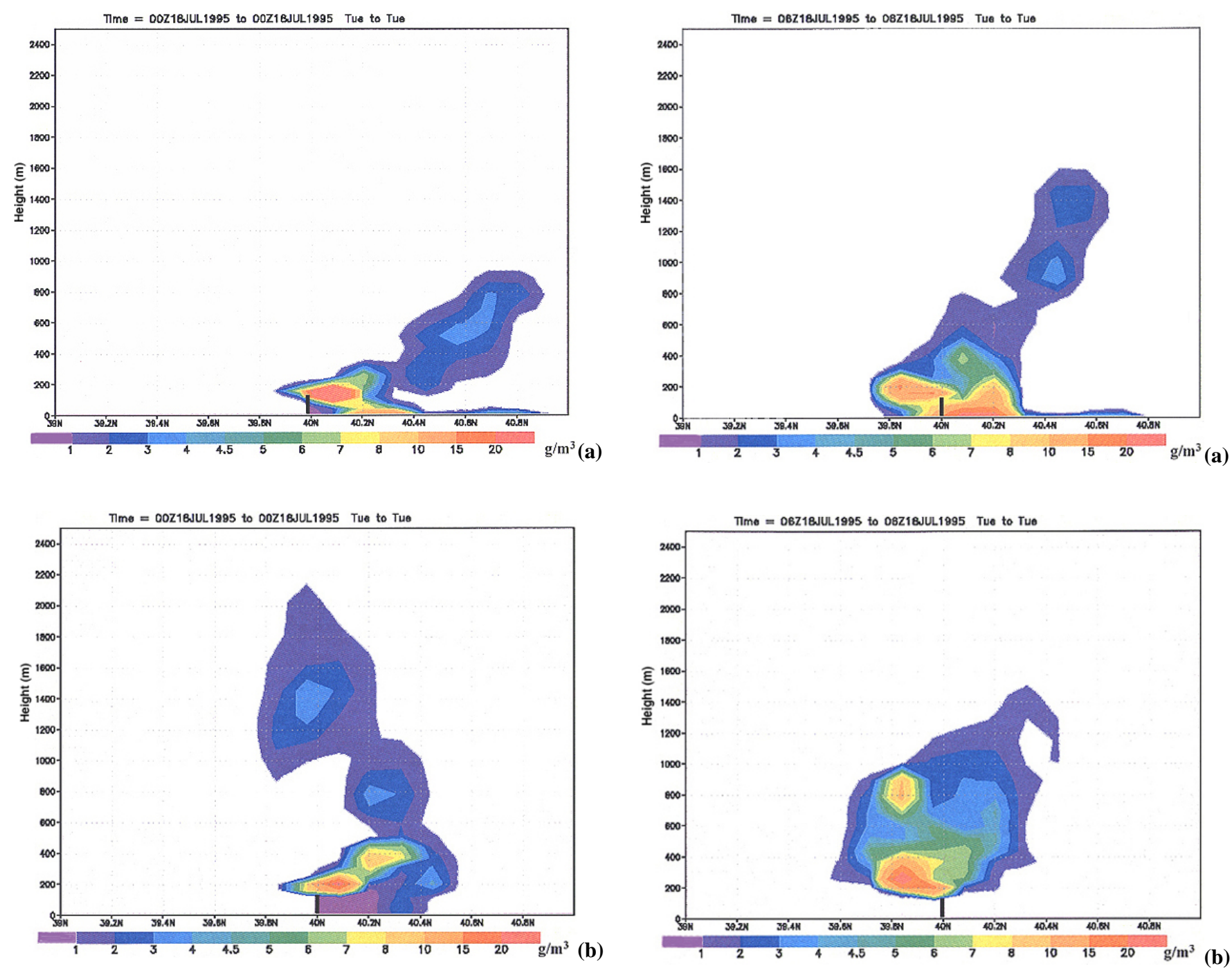

Fig. 8. Longitudinal cross section, spatially indicated in Fig. 2, of the simulated plume within grid $\mathrm{G}_{2}$ for both meteorological simulations, $S_{1}$ and $S_{2}$. Black line on lat. $40 \mathrm{~N}$ indicates the power plant chimney height. (a) simulation $S_{12}$ and (b) simulation $S_{22}$ of the vertical distribution of the simulated $\mathrm{SO}_{2}$ at Lon $0^{\circ}$ for the 00:00 UTC on 18 July 1995 (beginning of the second simulated day). At lower levels, the spatial distributions of the $\mathrm{SO}_{2}$ concentrations are different due to the drainage effect which the $\mathrm{S}_{12}$ simulation resolves but the $S_{22}$ simulation is not able to reproduce. Great differences in $\mathrm{SO}_{2}$ concentrations at ground level are observed. In case (a) ground concentrations are due to the emissions advected inland with the sea breeze on the previous day and returned towards the coast with the drainage winds.

important feature is the difference in the behaviour of the PBL parameterisation between both simulations. While in $\mathrm{S}_{12}$ the maximum height is $800 \mathrm{~m}$ a.g.l., in $\mathrm{S}_{22}$ it extends to 2100 m a.g.l. (Fig. 7).

This analysis of the meteorological data shows important differences in the mesoscale model outputs between the two meteorological approaches: In the first one $\left(\mathrm{S}_{12}\right)$, the high-

Fig. 9. Longitudinal cross section, spatially indicated in Fig. 2, of the simulated plume within grid $\mathrm{G}_{2}$ for both meteorological simulations, $S_{1}$ and $S_{2}$. Black line on lat. $40 \mathrm{~N}$ indicates the power plant chimney height. (a) simulation $S_{12}$ and (b) simulation $S_{22}$ of the simulated $\mathrm{SO}_{2}$ vertical distribution at Lon $0^{\circ}$ for 06:00 UTC on 18 July 1995. New emissions (plume aloft) are advected southward parallel to the coastline within a stable stratum of nocturnal drainage flow. Great differences in ground-level $\mathrm{SO}_{2}$ concentrations are observed. In case (a) ground concentrations are due to the emissions advected inland with the sea breeze on the previous day and returned towards the coast with the drainage winds.

resolution effects are included thanks to the two-way option between grids, and in the second one $\left(\mathrm{S}_{22}\right)$, the model resolves the $13.5 \mathrm{~km}$-grid resolution without any feedback from the inner domains (Fig. 7).

To check the implications of the two different meteorological approaches on the simulation of a plume from a point source located in an area like Castellón, both model outputs were employed to run two respective HYPACT simulations. 

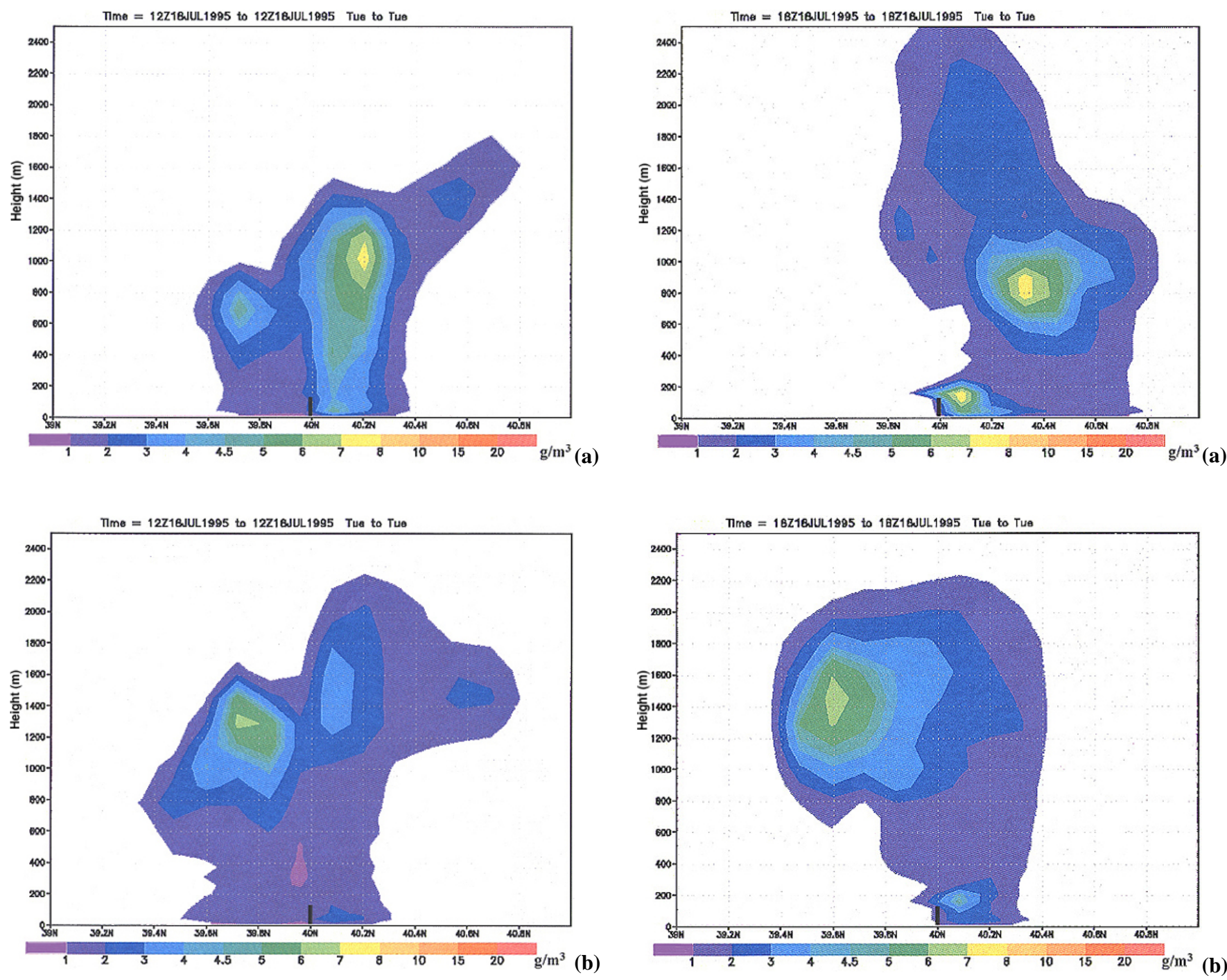

Fig. 10. Longitudinal cross section, spatially indicated in Fig. 2, of the simulated plume within grid $\mathrm{G}_{2}$ for both meteorological simulations, $S_{1}$ and $S_{2}$. Black line on lat. $40 \mathrm{~N}$ indicates the power plant chimney height. (a) simulation $\mathrm{S}_{12}$ and (b) simulation $\mathrm{S}_{22}$ of the vertical distribution of the simulated $\mathrm{SO}_{2}$ at Lon $0^{\circ}$ for 12:00 UTC on 18 July 1995. Under convective conditions with a well-developed sea breeze, the differences between the meteorological simulations of the PBL (Fig. 7) result in different mixing heights; thus, highly different plume fumigations on regions close to the point source are estimated.

The vertical distribution of the simulated $\mathrm{SO}_{2}$ concentration at Lon $0^{\circ}$, from 18 July 00:00 UTC to 18 July 18:00 UTC, differs greatly in both simulations $\left(\mathrm{S}_{12}\right.$ versus $\left.\mathrm{S}_{22}\right)$.

- At 00:00 UTC: In the lower levels, the spatial distributions of the $\mathrm{SO}_{2}$ concentrations are different due to the drainage effect which the $S_{12}$ simulation resolves but the $S_{22}$ simulation is not able to reproduce (Fig. 8).

- At 06:00 UTC: New emissions (plume aloft) are advected parallel to the coastline within a stable stratum

Fig. 11. Longitudinal cross section, spatially indicated in Fig. 2, of the simulated plume within grid $\mathrm{G}_{2}$ for both meteorological simulations, $S_{1}$ and $S_{2}$. Black line on lat. $40 \mathrm{~N}$ indicates the power plant chimney height. (a) simulation $\mathrm{S}_{12}$ and (b) simulation $\mathrm{S}_{22}$ of the vertical distribution of the simulated $\mathrm{SO}_{2}$ at Lon $0^{\circ}$ for 18:00 UTC on 18 July 1995. At the end of the daytime period on the second simulated day, differences between the simulations with respect to the maximum concentration height become evident. In the first case (with inner domain feedback) plume fumigations have higher concentrations than in the second case (without feedback from higher resolution domains). Moreover, the return flows of the sea breeze aloft are located at different heights and the simulated plumes aloft are located in different locations according to whether or not feedback effects are considered (differences in the mean plume axis of more than $0.7^{\circ}$ ).

of nocturnal drainage flow towards the South. Ground concentrations (emitted the previous day and swept towards the coast with the surface nocturnal winds) drain towards the South (Fig. 9). 
- At 12:00 UTC: A major difference is that $S_{12}$ shows significant impacts close to the point source, but $S_{22}$ shows no major impacts on the ground (Fig. 10).

- At 18:00 UTC: In $S_{22}$ the maximum concentration extends between 1200 and $1800 \mathrm{~m}$ in height while in $\mathrm{S}_{12}$ it reaches $1000 \mathrm{~m}$ with significant impacts close to the point source due to strong convective activity (Fig. 11).

These results show that in a coastal complex terrain area, the wind flow and the boundary layer estimated by the models can be very different depending on the meteorological scale resolved, which conditions strongly the pollutant behaviour simulated by the HYPACT Particle Model. The results shown were obtained on the basis of a release of particles at $175 \mathrm{~m}$ a.g.l (according to the estimated plume height), however, when we changed the release height to $25 \mathrm{~m}$ a.g.l, in order to represent the emission height of any urban pollutant, we obtained similar results (not shown). Thus, a model's ability to simulate the behaviour of pollutants emitted in the Castellón area, at least in the first $200 \mathrm{~m}$ a.g.l., will depend highly on its ability to correctly reproduce the daily cycle of the lower atmosphere.

These results are relevant in light of the fact that some of the meteorological approaches commonly considered to forecast urban air pollution episodes do not take into account the importance of the smaller scales for explaining the meteorology of sites like the Spanish Mediterranean coasts.

\section{Conclusions}

The availability of both $10 \mathrm{~m}$ a.g.l. meteorological data and experimental measurements aloft obtained by means of a vehicle equipped with a remote sensor, enabled us to validate a high-resolution simulation $\left(\mathrm{S}_{14}\right.$; with a grid size of $1.5 \mathrm{~km}$ ) of the daily behaviour of a Power Plant Plume (located in a coastal complex-terrain area) by means of the RAMS mesoscale model coupled with the HYPACT particle model.

This double model-validation procedure produced two main results: A) We were able to evaluate the degree to which the observed variate was accurately estimated by the simulated variate (index of agreement) on eleven sites located within the high-resolution domain, obtaining values of $77 \%$ for temperature and $82 \%$ for wind speed; and B) we were able to reproduce the daily cycle of a point-source plume in a coastal area with complex terrain because the highest horizontal resolution used enabled us to simulate the dynamic of the winds (sea breeze development and drainage winds).

Two additional simulations of the coupled models were performed using a grid size of $13.5 \mathrm{~km}$. In the first of these $\left(S_{12}\right)$ the high-resolution effects were included thanks to the ability of the model to work with two-way interactions between inner domains, while in the second $\left(S_{22}\right)$ there were no feedback effects with finer scales. As a result, in our simulation of pollutant dispersion in the lower layers of the atmosphere in a coastal complex-terrain area, we were able to compare the effects of two different meteorological approaches regarding the scales resolved. The main differences obtained were:

- Pollutant advections in the $\mathrm{S}_{12}$ and $\mathrm{S}_{22}$ simulations differ greatly during the early morning due to the difference in the drainage winds. This difference accumulates throughout the daily cycle because the emissions advected during the drainage flows are swept inland with the diurnal sea breeze development.

- The vertical distribution of the simulated $\mathrm{SO}_{2}$ concentration is very different in both simulations as a consequence of the discrepancies in PBL parameterisation behaviour: the $S_{12}$ simulation predicts much higher concentration values for the lower layers than the simulation without high-resolution effects.

The results show that in a complex-terrain coastal site, because of the strong effect of the meteorological interactions between the different scales on the integral advection and the turbulent dispersion of pollutants, using an inadequate scale to solve the meteorology can result in a very big gap in the simulation of lower-layer pollutant behaviour at urban scales.

Acknowledgements. This paper is dedicated in memoriam to D. Vicente Palau Blay (1929-2005). The authors would like to acknowledge the people from the Fundación CEAM who participated in the field measurements campaign. We are also indebted to M.-J. Sanz for kindly providing the RECAB-data for Fig. 1 and her continuous and valuable comments and support. This study has been mainly funded by the EC-research project FUMAPEX-EVK4CT-2002-00097, by the Ministerio de Ciencia y Tecnologia (Spain) REN2002-10681-E, and by the Generalitat Valenciana research project MEDICO-GV04B-069. The Commission of the European Communities also supported the experimental campaigns under the BEMA Step 1 project (1994-1995) 11096.95.07 F1PC.ISP E. The CEAM foundation is supported by the Generalitat Valenciana and BANCAIXA (València, Spain).

Edited by: A. Baklanov

\section{References}

AIR4EU.: Recommendations on Air Quality assessment by monitoring and modelling for regulated pollutants in Europe, Framework Programme VI, 2004-2006, http://www.air4eu.nl/index. html, 2004.

Alonso, L., Gangoiti, G., Navazo, M., Millán, M. M., and Mantilla, E.: Transport of tropospheric ozone over the bay of Biscay and the eastern Cantabrian coast of Spain, J. Appl. Met., 39 (4), 475486, 2000.

Assai, T. and Mitsumoto, S.: Effects of an inclined land surface on the land and sea breeze circulation: A numerical experiment, J. Met. Soc. Jpn., 56, 559-570, 1978. 
Atkinson, B. W.: Meso-Scale Atmospheric Circulations, Academic Press, 1-445, 1981.

BEMA (I): Biogenic Emissions in the Mediterranean Area, EUfunded project, Contrat: 11096.95.07 F1PC.ISP E., 1994-1995.

Bolle, H. J. (Ed.): Mediterranean climate: Variability and trends, Chapter 1, Springer-Verlag, Berlin (Germany), 2003.

Chaxel, E., Brulfert, G., Chemel, C., and Chollet, J. P.: Simulation of air quality in Chamonix valley (France): Impact of the road traffic of the tunnel on ozone production, 9th Conference on harmonisation within atmospheric dispersion modelling for regulatory purposes, Garmisch-Partenkirchen, Germany, 2004.

Chen, C. and Cotton, W. R.: A one-dimensional simulation of the stratocumulus-capped mixed layer, Boundary-layer Meteorol., 25, 289-321, 1983.

Chung, Y. S., Gallant, A., Fanaki, F., and Millán, M. M.: On the observation of Mount St. Helens Volcanic emissions, AtmosphereOcean, 19 (2), 172-178, 1981.

COBRA2000: $\mathrm{CO}_{2}$ budget and rectification airborne: Airborne measurements of regional to continental fluxes of $\mathrm{CO}$ and $\mathrm{CO}_{2}$, USA, http://www-as.harvard.edu/chemistry/cobra/, 2005.

COBRA-NA2003: $\mathrm{CO}_{2}$ budget and rectification airborne study: North America 2003, USA, http://www-as.harvard.edu/ chemistry/cobra/, 2005.

Dupont, E., Menut, L., Carissimo, B., Pelon, J., and Flamant, P.: Comparison between the atmospheric boundary layer in Paris and its suburbs during the ECLAP experiment, Atmos. Environ., 33, 979-994, 1999.

Eastman, J. L., Pielke, R. A., and Lyons, W. A.: Comparison of lake-breeze model simulations with tracer data, J. Appl. Met., 34, 1398-1418, 1995.

ECLAP: Étude de la Couche Limite en Agglomération Parisienne (Study of the Boundary Layer over the Paris Area), 1994-1995, This experiment is a partnership between the three French laboratories: Service d'Aéronomie [CNRS/Paris/Jussieu], Laboratoire de Meteorologie Dynamique [CNRS/Palaiseau], Environment Service of EDF [Chatou], http://euler.lmd.polytechnique. fr/menut/eclap95/eclap95eng.html, 2005.

ESCOMPTE: Expérience sur site pour contraindre les modèles de pollution atmospherique et de transport d'emissions, France, http://medias.obs-mip.fr/escompte/projet/index, Special Issue in Atmospheric Research, 74 (1-4), March 2005.

Fast, J. D.: Mesoscale modeling in areas of highly complex terrain employing a four-dimensional data assimilation technique, J. Appl. Met., 34, 2762-2782, 1995.

Fast, J. D. and Zhong, S.: Meteorological factors associated with inhomogeneous ozone concentrations within the Mexico City basin, J. Geophys. Res., 103 (D15), 18 927-18 946, 1998.

Fiore, A. M., Jacob, D. L., Bey, I., Yantosca, R. M., Field, B. D., Fusco, A. C., and Wilkinson, J. G.: Background ozone over the United States in summer: Origin, trend and contribution to pollution episodes, J. Geophys. Res., 107, D(15), doi:10.1029/2001JD000982, 2002.

FUMAPEX: Integrated Systems for Forecasting Urban Meteorology, Air Pollution and Population Exposure, Funded by the European Commission, 2002-2005, http://fumapex.dmi.dk/, 2005.

Gangoiti, G., Alonso, L., Navazo, M., Albizuri, A., Pérez-Landa, G., Matabuen, M., Valdenebro, V., Maruri, M., García, J. A., and Millán, M. M.: Regional transport of pollutants over the bay of Biscay: Analysis of an ozone episode under a blocking anticy- clone in west-central Europe, Atmos. Environ., 36, 1349-1361, 2002.

Gangoiti, G., Millán, M. M., Salvador, R., and Mantilla E.: LongRange transport and re-circulation of pollutants in the western Mediterranean during the project Regional Cycles of Air Pollution in the west-central Mediterranean Area, Atmos. Environ., 35, 6267-6276, 2001.

Gerbig, C., Lin, J. C., Wofsy, S. C., Daube, B. C., Andrews, A. E., Stephens, B. B., Bakwin, P. S., and Grainger, C. A.: Toward constraining regional-scale fluxes of $\mathrm{CO}_{2}$ with atmospheric observations over a continent: 1. Observed spatial variability from airbone platforms, J. Geophys. Res., 108 (D24), 4756, doi:10.1029/2002JD003018, 2003.

Guillot, P., Bonometti, G., Hasenjaeger, H., Van der Meulen, A., Hamilton, P. M., Haulet, R., Laurent, J., Sandroni, S., Cerutti, C., Giovanelli, G., Tirabassi, T., Vittori, O., and Piccinini, P.: First European Community campaign for remote sensing of atmospheric pollution, Lacq (France), 7-11 July 1975, Atmos. Environ., 13, 895-917, 1979.

Hanna, S. R. and Yang, R.: Evaluation of mesoscale models' simulations of near-surface winds, temperature gradients, and mixing depths, J. Appl. Met., 40, 1095-1104, 2001.

Hoff, R. M., Trivett, N. B. A., Millán, M., Fellin, P., Anlauf, K. G., and Wiebe, H. A.: The Nanticoke shoreline diffusion experiment, June 1978-III. Ground-based air quality measurements, Atmos. Environ., 16 (3), 439-454, 1982.

Kallos, G., Kotroni, V., Lagouvardos, K., and Papadopoulos, A.: On the Long-Range Transport of air pollutants from Europe to Africa, Geophys. Res. Lett., 25 (5), 619-622, 1998.

Kurita, H., Sasaki, K., Muroga, H., Ueda, H., and Wakamatsu, S.: Long-range transport of air pollution under light gradient wind conditions, J. Clim. Appl. Met., 24, 425-434, 1985.

Lalas, D. P., Asimakopoulos, D. N., Deligiorgi, D. G., and Helmis, C. G.: Sea-breeze circulation and photochemical pollution in Athens, Greece, Atmos. Environ., 17, 621-632, 1983.

Legg, B. J. and Raupach, M. R.: Markov-chain simulation of particle dispersion in inhomogeneous flows: the mean drift velocity induced by a gradient in Eulerian velocity variance, BoundaryLayer Meteorol., 24, 3-13, 1982.

Louis, J. F.: A parametric model of vertical eddy fluxes in the atmosphere, Boundary-Layer Meteorol., 17, 187-202, 1979.

Mahrer, Y. and Pielke, R. A.: The effects of Topography on sea and land breezes in a two-dimensional numerical model, Mon. Wea. Rev., 9, 1151-1162, 1977.

MAP-Riviera: Mesoscale Alpine Programme, Swiss National Science Foundation, 1999, http://www.iac.ethz.ch/en/research/map_ riviera/, 2005.

Martín, M., Plaza, J., Andrés, M. D., Bezares, J. C., and Millán, M. M.: Comparative study of seasonal air pollutant behaviour in a mediterranean coastal site: Castellón (Spain), Atmos. Environ., 25A (8), 1523-1535, 1991.

MECAPIP: Mesometeorological cycles of air pollution in the Iberian Peninsula, Funded by the European Commission, 19881991.

MEDUSE: Monitoring and prediction of the atmospheric transport and deposition of desert dust in the Mediterranean Region, Supported by the DG-XII of the EU, 1996-1998.

Mellor, G. L. and Yamada, T.: Development of a turbulence closure model for geophysical fluid problems, Rev. Geophys. Space 
Phys., 20, 851-875, 1982.

Menut, L., Coll, I., and Cautenet, S.: Impact of meteorological data resolution on the forecasted ozone concentrations during the ESCOMPTE IOP2a and IOP2b, Atmos. Res., 74, 139-159, 2005.

Menut, L., Flamant, C., and Pelon, J.: Evidence of interaction between synoptic and local scales in the surface layer over the Paris area, Boundary-Layer Meteorol., 93, 269-286, 1999.

Millán, M. M.: Ozone dynamics in the Mediterranean basin. A collection of scientific papers resulting from the MECAPIP, RECAPMA and SECAP Projects, Air Pollution Research Report 78, Brussels, 2002.

Millán, M. M.: Passive remote sensing of $\mathrm{SO}_{2}$, Proceedings from the EPA seminar - Workshop on prolonged elevated pollution episodes (PEPE), 19-23 March, 406-424, 1979.

Millán, M. M. and Hoff, R. M.: Dispersive correlation spectroscopy: a study of mask optimization procedures, Appl. Opt., 16, 1609-1618, 1977.

Millán, M. M., Alonso, L. A., Legarreta, J. A., Albizu, M. V., Ureta, I., and Egusquiaguirre, C.: A fumigation episode in an industrialized estuary: Bilbao, November 1981, Atmos. Environ., 18 (3), 563-572, 1984.

Millán, M. M., Mantilla, E., Salvador, R., Carratalá, A., Sanz, M.J., Alonso, L., Gangoiti, G., and Navazo, M.: Ozone cycles in the Western Mediterranean basin: Interpretation of monitoring data in complex coastal terrain, J. Appl. Met., 39 (4), 487-508, 2000.

Millán, M. M., Otamendi, E., Alonso, L., and Ureta, I.: Experimental characterization of atmospheric diffusion in complex terrain with land-sea interactions, International Journal of Air Pollution and Hazardous Waste Management, 37 (7), 807-811, 1987.

Millán, M. M., Artiñano, B., Alonso, L., Navazo, M., and Castro, M.: The effect of meso-scale flows on regional and long-range atmospheric transport in the western Mediterranean area, Atmos. Environ., 25A, 949-963, 1991.

Millán, M. M., Artiñano, B., Alonso, L., Castro, M., FernandezPatier, R., and Goberna, J.: Meso-Meteorological Cycles of Air Pollution in the Iberian Penisula, (MECAPIP) (Air Pollution Research Report 44, EUR No. 14834), European Commision DG XII/E-1, Rue de la Loi, 200, B-140, Brussels, 1992.

Millán, M. M., Salvador, R., Mantilla, E., and Artiñano, B.: Meteorology and photochemical air pollution in southern Europe: Experimental results from EC research projects, Atmos. Environ., 30 (12), 1909-1924, 1996.

Millán, M. M., Salvador, R., Mantilla, E., and Kallos, G.: Photooxidants dynamics in the Mediterranean basin in summer: results from European research projects, J. Geophys. Res., 102 (D7), 8811-8823, 1997.

Millán, M. M., Sanz, M. J., Calatayud, V., Palau, J. L., Diéguez, J. J., Pérez-Landa, G., Mantilla, E., Cerveró, J., and Chordá, J. V.: La calidad del aire en las comarcas de Els Ports-Maestrat, (Air quality in the Els Ports-Maestrat region), in Spanish, edited by: CEAM Foundation, 1-408, 2004.

Mizzi, A. P. and Pielke, R. A.: A numerical study of the mesoscale atmospheric circulation observed during a coastal upwelling event on 23 August, 1972, Part I: Sensitivity studies, Mon. Wea. Rev., 112, 76-90, 1984.

Moran, M. D.: Basic aspects of mesoscale atmospheric dispersion, in: Mesoscale atmospheric dispersion, edited by: Boybeyi, Z., Wit Press, London, 2000.
Ookouchi, Y., Uryu, M., and Sawada, R.: A numerical study of the effects of a mountain on land sea breezes, J. Met. Soc. Jpn., 56, 368-385, 1978.

PACIFIC2001: Air quality field study, Georgia Basin, Canada, August 2001, http://www.smc-msc.ec.gc.ca/projects/pacific2001/ index_e.html, 2005.

Palau, J. L.: Dispersión atmosférica de las emisiones de una chimenea alta en terreno complejo (Atmospheric dispersion of a tallstack plume on complex terrain), PhD Thesis (in Spanish), University of Valencia (Spain), edited by: CEAM Foundation, 366, 2003.

Pielke, R. A. and Uliasz, M.: Use of meteorological models as input to regional and mesoscale air quality models - limitations and strengths, Atmos. Environ., 32, 1455-1466, 1997.

Pielke, R. A.: Mesoscale meteorological modeling, 1st Edition Academic Press, New York, N.Y., USA, 1-612, 1984.

Portelli, R. V.: The Nanticoke shoreline diffusion experiment, June 1978-I, Experimental design and program overview, Atmos. Environ., 16 (3), 413-421, 1982.

POVA: POllution in Alpine Valleys, supported by Air de l'Ain et des Pays de Savoie, Région Rhône Alpes, launched in 2000.

RECAB: Regional Assessment and Modelling of the CARbon Balance within Europe, Funded by the European Commission, 2000-03.

RECAPMA: Regional cycles of air pollutants in the West-Central Mediterranean area, Funded by the European Commission, 1990-92.

Rotach, M. W., Calanca, P., Graziani, G., Gurtz, J., Steyn, D. G., Vogt, R., Andretta M., Christen, A., Cieslik, S., Connolly, R., De Wekker, S. J. F., Galmarini, S., Kadygrov, E. N., Kadygrov, V., Miller, E., Neininger, B., Rucker, M., Van Gorsel, E., Weber, H., Weiss, A., and Zappa, M.: Turbulence structure and exchange processes in an Alpine valley, The Riviera Project. Severe convective storms, Meteorological monograph no. 50, American Meteorological Society, 1367-1385, 2004.

Salvador, R., Calbó, J., And Millán, M. M.: Horizontal grid size selection and its influence on mesoscale model simulation, J. Appl. Met., 38 (9), 1311-1329, 1999.

Seaman, N. L.: Meteorological Modelling for Air-Quality Assessments, Atmos. Environ., 34, 2231-2259, 2000.

SECAP: South European cycles of air pollution, Support from the Directorate General XII of EU, 1992-1994.

Segal, M. , Yu , C.-H., Arritt, R. W., and Pielke, R. A.: On the impact of valley/ridge thermally induced circulations on regional pollutant transport, Atmos. Environ., 22, 471-486, 1988a.

Segal, M., Avissar, R., McCumber, M. C., and Pielke, R. A.: Evaluation of vegetation effects on the generation and modification of mesoscale circulations, J. Atmos. Sci., 45, 2268-2292, 1988 b.

Snyder, B.: Meteorological summary of the PACIFIC 2001 air quality field study, Atmospheric Science Section, Environmental Conservation Branch, Pacific and Yukon Region, Environment Canada, 2002.

Stauffer, D. R. and Seaman, N. L.: Use of four-dimensional data assimilation in a limited-area mesoscale model. Part I: Experiments with synoptic-scale data, Mon. Wea. Rev., 118, 12501277, 1990. 
Steyn, D. G.: Air pollution in coastal cities, in Air Pollution Modeling and its Application XI, Plenum Press, New York, 505-517, 1996.

TRACT: Transport of Pollutants over Complex Terrain EUROTRACT-1 (The European Experiment on the Transport and Transformation of Environmentally Relevant Trace Constituents over Europe) subproject, Joint project with the EC, 1986-1995.

T-TRAPEM: Transport and transformation of air pollutants from Europe to the Mediterranean Region, AVICENNE Initiative, Supported by the DG XII of EU, 1993-1995.

Uliasz, M.: Lagrangian particle modeling in mesoscale applications, Environmental Modeling II, edited by: Zannetti, P., Computational Mechanics Publications, 71-102, 1994.

Uliasz, M., Socker, R. A., and Pielke, R. A.: Regional modeling of air pollution transport in the southwestern United States, Environmental Modeling III, edited by: Zannetti, P., Computational Mechanics Publications, 145-182, 1996.

VOTALP: Vertical ozone transports in the Alps - VOTALP I (19961998) VOTALP II (1998-2000), Funded by the European Commission under Framework Programme IV, Environment and Climate, and by the Government of Switzerland, http://www.boku. ac.at/imp/votalp/, 2005.
Walko, R. L., Band, L. E., Baron, J., Kittel, T. G. F., Lammers, R., Lee, T. J., Ojima, D., Pielke Sr., R. A., Taylor, C., Tague, C., Tremback, C. J., and Vidale, P. J.: Coupled atmosphericbiophysics-hydrology models for environmental modeling, J. Appl. Met., 39, 931-944, 2000.

Weigel, A. P., Chow, F. K., Rotach, M. W., Street, R. L., and Xue, M.: High-resolution Large-Eddy Simulation of the Riviera valley: Assesment of the flow structure and the heat and moisture budgets, 11th Conference on Mountain Meteorology and the Annual Mesoscale Alpine Program (MAP), American Meteorological Society, USA, http://www.ametsoc.org/meet/fainst/ 11 mountain.html, 2004.

Weigel, A. P. and Rotach, M. W.: Flow structure and turbulence characteristics of the daytime atmosphere in a steep and narrow Alpine valley, Quat. J. Royal Met. Soc., 130, No. 62, 2605-2627, 2004.

Whiteman, C. D.: Breakup of temperature inversions in deep mountain valleys: Part I. Observations, J. Appl. Met., 21, 270-289, 1982.

Willmott, C. J.: On the validation of models, Physical Geography, 2 (2), 184-194, 1981 